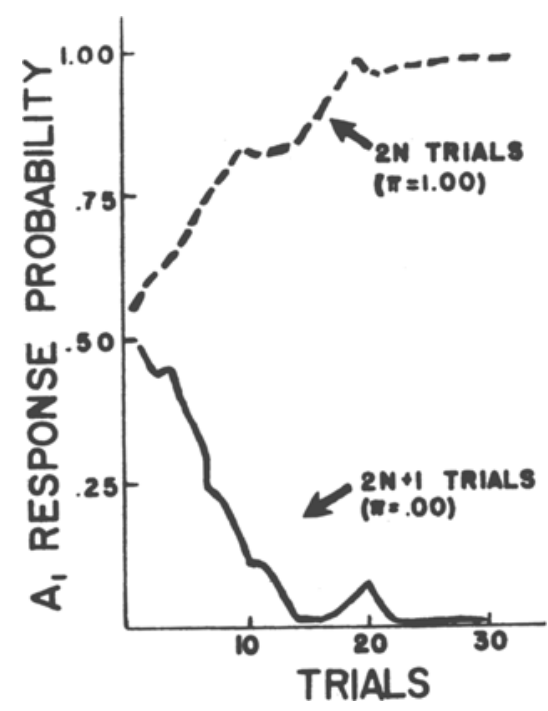

Fig. 2. Acquisition of $1.00-.00$ pure alternation in $\mathbf{3 0}$ trials.

\section{REFERENCES}

BUGGIE, S. E. Probability tracking of a linear periodic reinforcement schedule. Psychonomic Science, in press.

BURKE, C. J., \& ESTES, W. K. A component model for stimulus variables in discrimination learning. Psy chometrika, 1957, 22, 133-145.

BUSH, R. R., \& MOSTELLER, F. A model for stimulus generalization and discrimination. Psychological Review, 1951, 58, 413-423.

ESTES, W. K., \& BURKE, C. J. Application of a

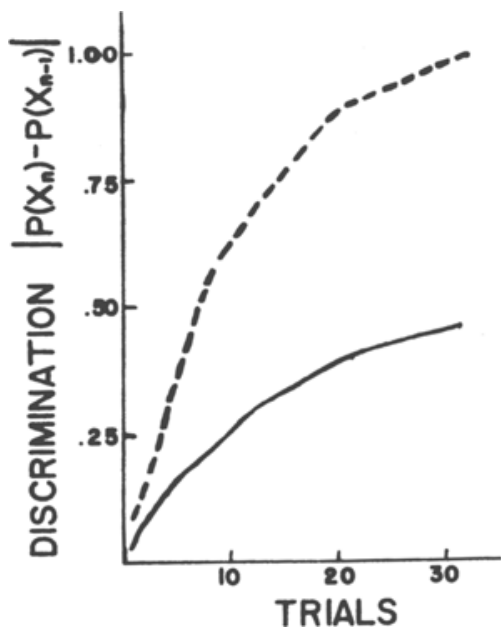

- - - 00-1.00 Pure Alternetion 10- .90 Probubilietice Alternetion

Fig. 3. Comparison of smoothed intertrial discrimination functions from pure and probabilistic sequences.

statistical model to simple discrimination learning in human subjects. Journal of Experimental Psychology, 1955, 50, 81-88.

ESTES, W. K., BURKE, C. J. ATKINSON, R. C., \&

FRANKMANN, J. P. Probabilistic discrimination learning. Journal of Experimental Psychology, 1957, 54, 233-239.

NOTES

1. Now at the University of Oregon, Eugene
Ore. 97403. The author gratefully acknowledges the helpful advice offered by Dr. Robert S. Witte of San Jose State College, and Mr. Charles Bebeau of the University of Colorado. The manuscript was prepared while the author was supported under Contract No. F44620-67-C-0099 between the University of Oregon and the Advanced Research Projects Agency of the Department of Defense. 968

2. Estes, W. K. Personal communication, May

\title{
Variability of signal detection measures with noise type
}

PATRICK H. McCANN, Naval Personnel Research Activity, San Diego, Calif. 92152

The effects of continuous noise vs intermittent noise on $S s$ performing an audio-visual checking task were examined using TSD (Theory of Signal Detectability) measures of performance. TSD measures were relatively stable for all Ss during both intermittent and continuous noise conditions and closely approximated the values which would be expected in a psychophysical setting. During the last $20 \mathrm{~min}$ of the duty period, there was a corresponding increase in the Ss'response criterion.

An approach to the study of noise effects on vigilance is offered through the theory of signal detectability (Swets, 1964). TSD provides a method for treating false alarm or commission data generated from vigilance tasks. Detection performance is considered as a judgment process in which stimuli are classed by the Os as signals or nonsignals as a function of a criterion that the 0 employs. The criterion is a statistical cut-off between two overlapping normal distributions which represent signal and nonsignal stimulation. An $O$ will utilize a given criterion and will make errors of omission and commission at predictable frequencies. The $O$ 's response criterion (" $\beta$ ") and his discriminative efficiency (" $d$ ") may be computed as measures of vigilance performance. The value $\mathrm{d}^{\prime}$ is the distance in standard scores between the mean of the nonsignal distribution and the mean of the signal distribution. The percentage of detections, $P_{D}$, and percentage of comissions, $P_{C}$, represent areas of signal and nonsignal normal distributions, respectively, for which standard scores may be obtained from a table of normal curve functions. The distance in standard scores of $P_{D}$ to the left of the signal distribution mean plus that of $P_{C}$ to the right of the nonsignal distribution mean equals $d^{\prime}$. The response criterion, $\beta$, is the ratio of the ordinate of the $P_{D}$ point on the signal distribution abscissa to the ordinate of the $\mathrm{P}_{\mathrm{C}}$ point on the nonsignal distribution abscissa. Ordinate values are available from a table of normal curve functions.

Depending upon which noise condition, intermittent or continuous, produces decreased vigilance performance, $d^{\prime}$ and $\beta$ will vary accordingly. Discriminatory efficiency, $d^{\prime}$, should increase and the response criterion, $\beta$, also may increase under the noise condition most conducive to signal detection. The present study tests this hypothesis and examines the relationship between $\beta, \mathrm{d}^{\prime}$, and noise type.

\section{METHOD}

An audio-visual checking task was used upon which the performance of 20 Ss was measured. The task consisted of checking a list of seven-digit numbers against an audio presentation of the numbers. The signal to be detected was a discrepancy between a 
number as it appeared on the checklist and the audio presentation of the number. The correct experimental response, or signal detection, consisted of striking out the digit which differed from that presented aurally, for example, 3245679 presented aurally vs 3245779 appearing on the checklist.

Subjects performed for a $1 \mathrm{~h}$ period. The hour duty period was divided into three 20-min subperiods of signal presentations in which a quiet, contimuous, or intermittent noise background was present.

Each of the seven-digit numbers was presented in $1.5 \mathrm{sec}$. The schedule of presenting numbers and signals (discrepancies) was the same for all three subperiods. There were 100 number presentations during each subperiod consisting of $\mathbf{2 0}$ signals and 80 nonsignals.

Throughout the 20-min subperiod of intermittent noise, background monotones $(520 \mathrm{~Hz}$ and $50 \mathrm{~dB})$ of 1.5 sec duration were interspersed between all number presentations. Intermittent tones were presented randomly except for 10 tones which occurred simultaneously with 10 signal presentations. The pairing of 10 signals, or $50 \%$, and tones was done to determine if the noise frequency and intensity employed in the experiment produced a masking effect on signals. The other 10 signals of this subperiod did not occur simultaneously with monotones.

During the 20-min continuous noise subperiod, a steady monotone, $520 \mathrm{~Hz}$ and $50 \mathrm{~dB}$, clearly distinguishable from the number presentations, was present.

Only the seven-digit numbers were presented during the quiet control subperiod. The experimental room and immediate surrounding area were made free of disturbances.

Two tapes were recorded to partially counterbalance the order in which the three subperiods of the 1-h duty were presented. They were as follows: Quiet-IntermittentContinuous and Quiet-ContinuousIntermittent. Ss were divided equally to serve under the two orders of background conditions.

\section{PROCEDURE}

The task was administered once each to two groups of male and female Ss, high school graduates between 20 and 30 years of age. To eliminate collaboration between Ss, Ss were seated at individual cubicles in the test room with a pencil and the checklist. The audio stimuli were presented to Ss over loudspeakers. Prior to starting the experiment Ss were tested for normal hearing and vision. Ss were oriented on the task to be performed with oral and written instructions.

Subjects were informed that they were about to take a test to measure numerical checking ability, and the test purpose was
Table 1

Values of $d^{\prime}$ and $\beta$ for each $S$ during the Intermittent and Continuous Noise Subperiods

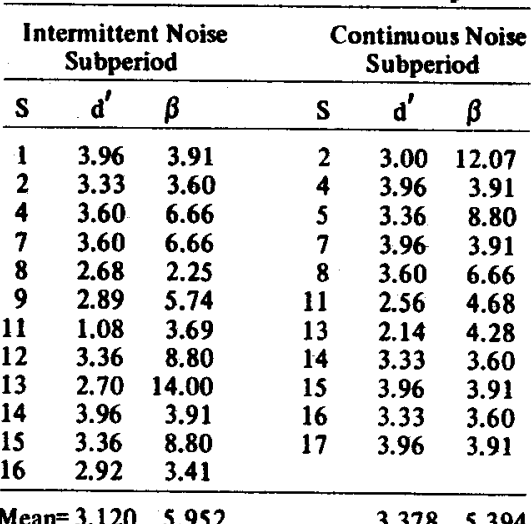

Table 2

Values of $d^{\prime}$ and $\beta$ for each $S$ during Last $40 \mathrm{~min}$

\begin{tabular}{|c|c|c|c|c|c|}
\hline \multicolumn{3}{|c|}{ Second $20-\mathrm{min}$ Period } & \multicolumn{3}{|c|}{ Last $20-\min$ Period } \\
\hline $\mathbf{S}$ & $\mathrm{d}^{\prime}$ & $\beta$ & $\mathbf{S}$ & $d^{\prime}$ & $\beta$ \\
\hline 1 & 3.96 & 3.91 & 2 & 3.00 & 12.07 \\
\hline 2 & 3.33 & 3.60 & 4 & 3.96 & 3.91 \\
\hline 4 & 3.60 & 6.66 & 5 & 3.36 & 8.80 \\
\hline 7 & 3.60 & 6.66 & 7 & 3.96 & 3.91 \\
\hline 8 & 2.68 & 2.25 & 8 & 3.60 & 6.66 \\
\hline 9 & 2.89 & 5.74 & 11 & 1.08 & 3.69 \\
\hline 11 & 2.56 & 4.68 & 12 & 3.36 & 8.80 \\
\hline 13 & 2.14 & 4.28 & 13 & 2.70 & 14.00 \\
\hline 14 & 3.33 & 3.60 & 14 & 3.96 & 3.91 \\
\hline 15 & 3.96 & 3.91 & 15 & 3.36 & 8.80 \\
\hline 16 & 3.33 & 3.60 & 16 & 2.92 & 3.41 \\
\hline 17 & 3.96 & 3.91 & & & \\
\hline
\end{tabular}

Mean=3.278 4.400

$3.205 \quad 7.087$

explained. They were told that throughout the test period various background tones might be heard which should be ignored. A 5 -min trial period preceded the test to insure that $S$ s recognized and responded to discrepancies (signals) correctly.

In case $S$ lost his place, he was instructed to indicate with a check $(\mathrm{X})$ mark the last number he monitored and to indicate with a " $B$ " the number at which he resumed his checking progress. Ss were required to give up their watches at the beginning of the test as the approximate length of the duty period may have been known to the $S$ which could have possibly affected performance.

RESULTS AND DISCUSSION

Of the $20 \mathrm{Ss}$ in this experiment, 12 in the intermittent subperiod and 11 in the continuous subperiod emitted at least one false alarm and made fewer than $100 \%$ detections. These are the only Ss for whom exact TSD measures can be determined. The remaining Ss, however, are also important for the TSD analysis. There were four $\mathrm{Ss}$ in both the intermittent and continuous noise subperiods who detected all 20 signals correctly and made no commission errors in response to 100 nonsignal stimuli. The TSD analysis is based on a total of 100 stimuli, 20 of which are signals, numbers with discrepant digits, and also nonsignals because Ss had the opportunity to make an error of omssion and commission within the same stimulus number. The four "perfect" Ss of each subperiod make it possible to estimate a minimum $\mathbf{d}^{\prime}$ and corresponding $\boldsymbol{\beta}$.

The detection of all 20 signals can be treated as being at least as great as $\mathbf{1 9 . 5}$ of 20 detections. So the lower limit on the probability of detection is: $P_{D}=(19.5 / 20.0)$ $=0.975$.

The absenxe of commission errors can be treated as the committing of fewer than 0.5 false positives, so the maximum commission error probability is: $P_{C}=(0.5 / 100)=0.005$.

With these limiting probabilities $d^{\prime}$ and $\beta$ may be defined and calculated. The variable, $d^{\prime}$, is equal to the distance between the signal and nonsignal distribution means, divided by the standard deviation of each distribution. The S's response criterion, or $\beta$, is the ratio of the ordinate of the signal-present distribution to the ordinate of the signal-absent distribution, at the point where the criterion is placed.

For the limiting probabilities of $P_{D}$ and $P_{C}$ above $: d^{\prime}=4.535$ and $\beta=4.030$.

It is important that $\beta$ is theoretically independent of $\mathrm{d}^{\prime}$ for rational behavior. It is only affected by the importance which the $S$ places on detecting signals as opposed to avoiding commission errors, and by the probability which he assigns to the occurrence of a signal as opposed to a nonsignal. A drop in detections alone can be due to a decrease in $\mathrm{d}^{\prime}$ with constant $\beta$, or a rise in $\beta$ with a constant $d^{\prime}$.

The TSD measures obtained for Ss during the intermittent and continuous noise subperiods are presented in Table 1. The detectability index, $d^{\prime}$, was not significantly greater for the continuous noise period. Table 2 lists the $d^{\prime}$ and $\beta$ values for Ss during second and last $20-\mathrm{min}$ periods of the $1 \mathrm{~h}$ duty period. The $d^{\prime}$ measure did not vary significantly between these periods. However, $\beta$ did increase significantly from the second to the last 20-min period (MannWhitney $U$ test, $p<.05$ ), indicating that Ss did become more cautious with time at work.

Inspection of Table 1 reveals that the TSD measures, $d^{\prime}$ and $\beta$, are fairly stable across all Ss. The "true" $d$ ' of at least 4.535 was suggested by the data of the "perfect" Ss. This value should have been approximated by all Ss with most individual differences in $\beta$; however, the overall mean $\mathrm{d}^{\prime}$ for Ss was 3.390, considerably less than that of our perfect Ss. Our obtained overall mean Beta value of 5.708 exceeds the $\beta$ of 4.030 for our ideal Ss.

\section{REFERENCE}

SWETS, J. A. Signal detection and recognition by' human observers. New York: Wiley, 1964. 